\title{
BLACK ENGLISH AND THE AMERICAN VALUE SYSTEM
}

\author{
GLENDON F. DRAKE
}

\section{San Diego State University}

The strategy of enlightened bi-dialectalism used by the schools in the United States to deal with the problem of Black English is a significant attempt at social engineering. This attempt is motivated by basic linguistic attitudes which reflect the American value system. Bi-dialectalism is a melting-pot theory of American culture, an attempt to implement the American Dream of social mobility for all. This value operates in concert with the school's prescriptive linguistic attitude, through a co-optive strategy, against a pluralistic ethic. Bi-dialectalists err not in supposing code-switching is feasible, but in supposing that the school is the primary and proper agency for implementing code-switching. The failure of twentieth-century relativism to penetrate the school's value system so far as "English" is concerned has frozen the school in the nineteenth century in terms of linguistic attitudes.

The 1960's and early 70's in America have seen one of the largest and most significant attempts at social engineering ever undertaken in this culture. It is seldom recognized as such, because it usually goes by the name of something like "teaching standard English as a second language (or dialect)." The project seems, then, merely a technical linguistic or pedagogical problem. But I should like to submit that it is an issue that goes to the core of American values and aggravates basic American tensions.

The task on the part of schools has been to compel speakers from minority groups, notably urban ghetto blacks, to acquire so-called Standard English as a replacement or alternative for their native non-standard dialect in order that these people might experience more success in school and in the job market, as it is assumed that their clear failure as a group in these areas is directly related to the negative reaction to their speech or to the inadequacy of their speech.

\section{Black and Standard English}

To most educators, Black English and Standard English are hard and clear realities. To most linguists-with a few notable exceptions in the case of Black English-they are fictions, sometimes useful fictions, but fictions nonetheless. The evidence seems clear that the concept "Standard English" in America is an objective fiction. Perhaps American educators have confused the relative homogeneity of American speech (i.e., relative compared to cultures similar to ours such as Britain, France, or Germany) with the existence of a standard. More likely, however, the strength and persistence of the prescriptive linguistic doctrine has structured the perception of the American educator. Consequently, as a practical matter, "standard" becomes the cultivated social dialect of the particular region where it is applied, or an abstract ideal-"schoolmarm English" -in the case of most school rooms. 
The objective reality of Negro Nonstandard is still a research question. William Stewart and others have presented evidence that the dialect spoken by many urban blacks has features of West Indian Creole and African antecedents. Other linguists view Black English as migratory uneducated Southern speech. But, whichever, the speech of some black people has become a grave social problem because of what Dwight Bolinger has termed "the horizontal imposed on the vertical" (1968: 149-150). The geographical migration of poor, uneducated southern blacks to the urban North and West has brought two divergent regional dialects into contrast. At the same time, the social dialect of the migrants is characteristically that termed "uneducated" which is recognized as nonstandard even in the home southern region. Therefore, in the urban North the speech of blacks and poor migrant whites is twice alien, once regionally and once socially. This establishes as great a linguistic contrast as can be created in the homogeneous American English speech community.

The practice of racial discrimination and segregation help explain the persistence of Negro Nonstandard, sometimes even into the third or fourth generation. Because migrant blacks were forced into ghettos and denied jobs and education which could lead out of the ghetto, the southern, uneducated speech remained intact. As the same people habitually talked to each other year after year, generation after generation, the community habits of pronunciation, morphology, syntax, and vocabulary were enforced and maintained.

As a practical matter, whatever differences exist between Negro Nonstandard and Standard are few in number, exist in deep structure with relatively little reflection in the performance of the speech. Consequently, the speech of lower-class black ghetto dwellers is mutually intelligible with any other American English dialect-social, regional, or occupational. The evidence is clear on this point.

But, as we shall see, the linguistic reality is not nearly as important as what Americans believe about speech and their attitudes toward that belief.

\section{Deficit vs. Difference}

One of the most important attitudes of Americans about Black English has been the deficit notion.

This very popular notion can be summed up in these terms: "Negro children from the ghetto are said to receive little verbal stimulation, are said to hear very few well formed sentences, do not know the names of common objects, cannot form concepts or convey logical thoughts"' (Labov, 1969: 60).

In the 1960 's, teachers, because of the concern about, if not the practice of, racial integration, became aware of a great body of speech which was clearly not "standard," read "correct" in more traditional jargon. Since it is not in the nature of the prescriptive attitude to recognize diversity-difference-the difference was perceived as deficit.

Sociolinguists have been successful in debunking the deficit theory as a "modern mythology of educational psychology." The most impressive of the debunkings is William Labov's "The Logic of Non-standard English," in which Labov concludes that:

“... these [deficit] notions are based upon the work of educational psychologists who know very little about language and even less about Negro children. The concept of verbal deprivation has no basis in social reality; in 
fact, Negro children in the urban ghettos receive a great deal of verbal stimulation, hear more well formed sentences than middle-class children, and participate fully in a highly verbal culture; they have the same basic vocabulary, possess the same capacity for conceptual learning, and use the same logic as anyone else who learns to speak and understand English (1969: 60).

\section{Eradication}

But while the deficit theory existed unchallenged, it motivated much remedial type activity in the nation, such as Operation Head Start; and in the school it was responsible for the eradication movement. That is, teachers sought simply to eradicate the native dialect of minority people and replace it with Standard English.

Eradication as a strategy for dealing with Black English had a short life and little influence among the leaders and theorists of the English-teaching fraternity. This is not to say, of course, that the rank and file English teacher engaged from day to day in the pit did not remain an eradicationist. This sort of lag is to be expected in an institution as conservative as the school, and especially within the discipline of English. But the thrust in the sixties and early seventies is away from eradication. The reason for this is that the strategy is linguistically naive. Of course, most English teaching, especially since the middle of the nineteenth century, has been notable for its linguistic naiveté. But finally, after generations of effort, linguists are getting a hearing from teachers. This hearing has led away from eradication toward the strategy of the present-“enlightened bi-dialectalism."

\section{Enlightened Bi-dialectalism}

The "enlightened" in the label refers to what teachers have learned about language from linguists. Linguists maintain that all dialects, including the dialect spoken by many black ghetto dwellers, are fully developed, sophisticated, complex language systems. The dialect of the lower-class black serves him well in the ghetto, and if the school eradicates it and replaces it with so-called Standard, which might serve him well in school, he would be in trouble at home for abandoning the dialect of his family and peers. Yet teachers claim they know very well that if blacks are to become socially mobile and if they are to find success in the school, they must acquire "Standard English." Therefore, bi-dialectalism has become the meeting ground between linguists and enlightened teachers. The solution has been to make the student proficient in the standard that he will need to get plugged into the American Dream and at the same time allow him to use his "home" dialect in the appropriate places.

In recent years, this effort in the school to create functional bi-dialectalism has been enormous, often aided by Federal legislation and private foundation grants, and the effort continues to grow. The energy of bi-dialectalism seems to signal something greater than mere pedagogy at work.

A careful investigation of the phenomenon reveals two sets of related motives. First of all, the bi-dialectal movement is a manifestation of the traditional prescriptive drive which in the educational institution and in the general culture has for a 
very long time been in tension with the descriptive notion of language. Second, the prescriptive motive is entwined with certain social goals which are usually referred to when the term "American Dream" is trotted out.

Now first regarding the prescriptive attitude: it has long been the established notion in our schools, though often challenged vigorously by descriptive notions. The prescriptive notion holds that linguistic behavior should accord with an abstract notion of correctness, so that the language of the student conforms to the rules of some absolute standard. This doctrine is usually known as "traditional grammar" and is painfully familiar to anyone who has been at the mercy of an American school in the last one hundred and twenty years. The descriptive notion holds with describing linguistic structure, change, and diversity to students rather than prescribing how they should behave. This doctrine grew out of the twentieth-century "scientific" school of linguistics and has had little influence in the school, although its proponents have striven mightily to make an impression on that institution.

The prescriptive basis for bi-dialectalism is easily seen in the argument for it, for a basic inconsistency appears-such inconsistency is characteristically a signal of a covert motive lurking beneath the rational discourse. In the argument for bi-dialectalism, we have the proposition derived from linguistic evidence that all dialects are able to perform the communication function. The teacher grants this, yet assigns the use of Standard to all socially important roles, telling the students, in effect: "Your native dialect is fine for home use and for activities in the ghetto, but when you try to achieve anything in school or in the larger culture use the standard I'm trying to teach you." This "separate but equal" doctrine is a familiar one to blacks, and we may be sure that many blacks read the covert message it bears.

The advocates of bi-dialectalism ". . f feel that it is their duty as educators to provide the learner with the alternatives to make his life what he wants it to be" (Shuy, 1969: 83). Yet, the alternatives are nearly always presented so that there is not genuine choice-every effort is made to push the student toward the standard. For example, in the same article just quoted, the author, Roger Shuy, notes that most current materials deal with pronunciation differences between Standard and Nonstandard, although linguists know that grammatical differences count more heavily toward social judgments than phonological or lexical differences. "If grammatical matters count more heavily in social judgments, it seems reasonable to assume that grammatical matters should receive high priority in materials development" (Shuy, 1969: 83). This is a characteristic example of how the linguist has been co-opted by the school to serve its prescriptive goal. Shuy, one of the most able sociolinguists, begins this particular article with an appreciation of Nonstandard, then moves to an attack on eradication. "The reason," he says, "for the low esteem in which nonstandard English is held derives from mankind's lowest points. Snobbery, hatred, inequality, racism and jealousy are all likely candidates" (Shuy, 1969: 83). Yet he ends his article by telling teachers how they can best use linguistic materials to engineer in the lingua franca of the classroom.

In other places this relationship between the linguistic scientist and the bi-dialectal effort is more explicit. The Detroit Dialect Study described one of its objectives this way:

To describe the specialized linguistic features of the various English-speaking sub-cultures of Detroit ... linguistic sociologists and educators [agree] that a sound procedure for any kind of English language engineering must begin with the actual speech of the various classes, age groups, races, occupation groups and immigrants. Once the phonology, grammar, and lexicon have been adequately described, pedagogical applications can be made with efficiency and accuracy (Shuy, Wolfram, and Riley, 1967: 1). 
Linguists know better than anybody else that "making children who talk wrong get right with the world has traditionally been the work of English teachers" (Sledd, 1969: 1307), and linguists must know that their data will be used for this prescriptive purpose. They know-but the social motives for the engineering task seem too formidable and important for them to ignore.

J.L. Dillard, a linguist and Director of the Urban Language Study of the Center for Applied Linguistics, has said that, "It seems fortunate that [a study of Negro Non-standard urban language] was conceived, on partly independent grounds, at about the time that the educational and social problems of these Negroes began to assume importance to the nation as a whole" (Dillard, 1966: 1). It seems strange that a professional of J.L. Dillard's frequently demonstrated ability and acuteness should be naive enough to believe that the study and the problems should be even partly independent. The press in the 1960's-for example, the New Republic of March 25, 1967-would have told him of the relationship in a report on legislation enacted by the 89th Congress setting up a program for teaching "Standard English" to urban Negroes to make them more suitable for the job market (1967: 1). If one recalls that at this time the smoke from Watts and Detroit was still acrid in the nostrils of the white establishment, Dillard's ingenuousness becomes more clear. Indeed, Dillard must have read his own colleagues and learned that, "By far the most commonly stated reason for teaching children to be biloquial [bi-dialectal] is to enable them to ascend the social ladder" (Shuy, 1969: 82).

The point is that some linguists and enlightened teachers see themselves as "social realists." (One is reminded of $C$. Wright Mills' concept of "crackpot realism".) No matter what the viability of Black English as a speech system, "It seems clear ... that it is necessary to teach standard English to non-standard speakers. They must know the language of the country if they are to become a part of the mainstream of that society ... since standard English is the language of the mainstream it seems clear that knowledge of the mainstream system increases the likelihood of success in the mainstream culture" (Baratz, 1969: 76). The Detroit Dialect Study points out that:

It is the conviction of an increasing number of linguists that the speech of Americans is one of the most important clues to upward social mobility. Sociologists, psychologists, educators and others have pointed to a large number of indices of social stratification based on behavior, attitudes and abilities. But, to the linguist none of these indices seems as significant as language itself, for not only does it underly the very structure of communication, but it is also frequently beneath the surface of consciousness (Shuy, Wolfram, and Riley, 1967: $1)$.

It is this conviction, apparently, that leads so many linguists to work so hard to develop materials to help the schools in their linguistic engineering.

Says the Detroit Dialect Study elsewhere:

... the long cherished notion of the mutually exclusive tasks of linguist and educator is in serious question. Linguists cannot divorce themselves from matters of educational sequencing for their work yields very clear implications for the classroom.... [The linguist's] clear responsibility is to identify the indices of social stratification... and to determine the best sequencing of instruction through the discovery of the speaker's conscious control of these features (Shuy, Wolfram, and Riley, 1967: 1). 
Thus do the linguist and the teacher place themselves in support of the corporate state. And thus it becomes clearer that bi-dialectalism is a political instrument. It is, as Robert Kaplan has noted, an attempt on the part of the power structure ". . . to expedite assimilation and thereby to prevent the use of force and the disruption of the status quo" (Kaplan, 1969: 165).

All of this may seem on the surface perfectly straightforward, and, indeed, the best means of dealing with a serious social problem. Certainly it seems so to most of the public and to many intelligent, well-intentioned teachers and linguists. Some few observers, among them some linguists, are beginning to have doubts.

\section{Melting Pot vs. the Counter-Culture}

Bi-dialectalism is a creature of the melting-pot theory of American culture, an attempt to help implement the American Dream of social mobility for all. How then can anyone sensitive to the historical and present plight of black Americans be skeptical of the effort? The skepticism can be sorted out under three rubrics: 1) technical linguistic objections; 2) social-psychological objections; 3) moral objections.

The technical objections to bi-dialectalism would take a very long time to detail, and since I am more concerned with attitudes in this discussion, I will say only that the objections are based primarily on an uncompromising linguistic view of the notion of bi-dialectalism-a view that is informed by the strong commitment to twentieth-century cultural relativism, most disinclined to be co-opted by the school and made to adjust to an essentially prescriptive goal for the sake of "social realism." Linguistic critics of bi-dialectalism cannot forget that the linguistic evidence indicates that differences between so-called Negro Nonstandard and so-called Standard are not racial in the long view, and the differences are not major impediments to communication between two groups of people (Kaplan, 1969: 165). They are aware of the fact that there is no reliable description of the Negro Nonstandard (or even of Standard English) on which to base the materials for the linguistic engineering (Sledd, 1969: 1313). Some linguists cannot ignore what they know of the nature of linguistic authority: that the paltry bit of formal authority the school exerts cannot have much effect against the enormous influence of the informal authority that the speaker meets elsewhere in the speech community (Sledd, 1969: 1313). Some linguists are unimpressed with what they consider the negligible results of bi-dialectalism compared to the enormous time and energy invested in it by the schools (Kochman, 1969: 87). In short, there is doubt that the project is technically possible in the school. The fact that bi-dialectalism remains so important in education in the face of so little accomplishment is testimony to its felt social urgency. This perception may have been in the mind of the black student who remarked cynically to Kenneth Goodman: "Ya man, alls I gotta do is walk right and talk right and they gonna make me president of the United States"' (Goodman, 1967: 45).

It is important to keep the perception of such a student in mind when considering the second argument against bi-dialectalism: the social and psychological objections. After all, what the assimilationist accomplished with Standard English 
as a second dialect at most is the ability on the part of a black to avoid some linguistic forms which are stigmatized because the people who use them are (Kochman, 1969: 157). Kenneth Goodman points out that:

In essence the child who is made to accept another dialect for learning must accept the view that his own language is inferior. In a very real sense, since this is the language of his own parents, his family, his community, he must reject his own culture and himself, as he is, in order to become something else. This is perhaps too much to ask of any child. Even those who succeed may carry permanent scars. The school may force many to make this choice between self-respect and school acceptance. And all this must be accomplished on the faith of the learner, that by changing his language he will do himself some good (Goodman, 1967: 45).

Bi-dialectal programs threaten to demand the destruction of a legitimate culture and of the legitimate identity of blacks as the price of integration (Baratz and Baratz, 1969: 151). What has given the white middle-class community the right to ask that the black pay this price to achieve identity?

The notion of a pluralistic society is as viable as the melting-pot notion and certainly more obtainable as a social reality. Cultural and linguistic differences are not incompatible with political, social and educational equality. A freely discovered identity for blacks seems more desirable than an imposed identity. The tension is between a minority and a majority, both of whom recognize the importance of language. The difference is that the majority seeks to assimilate the minority through linguistic standardization as a means to other kinds of standardization. The minority may, if given the chance, seek identity from that language (Kaplan, 1969: 86). This, of course, is a manifestation of an old and characteristic tension in American cultural values-the tension between the puritan-genteel continuity and the romantic thrust. But this and the fact that the puritan drive is institutionalized in the school is no reason to tolerate what is essentially an attack on minority culture.

This is especially true if one notes the evidence which suggests that the verbal environment in the ghetto and in certain other minority sub-cultures may be better models of verbal achievement than the middle-class model that seeks to replace the minority models. Labov's findings suggest this. Thomas Kochman has done cross-cultural comparisons and concluded that black ghetto culture, for example, rewards and values active, accomplished verbal behavior more than middle-class culture. While middle-class culture rewards and values writing more highly, it would replace the active verbal ethos of the black with the white passive-receptive-obedient ethos of the middle-class school system (Kochman, 1969: $89 \mathrm{ff}$.).

Third, it is not difficult to see how these objections easily drift into the area of moral concerns. The evidence that the bi-dialectal programs are educationally wasteful and socially destructive alone place the programs in the area of moral concern. There are other and related concerns as well. Bi-dialectalism forces the teacher and the school to make choices which are properly not theirs about the future, values, and identity of the students. One example is the recent decision of the University of California, Irvine, to consolidate its EOP program into the general administration so that minorities can be brought into the "educational mainstream," in the language of the Irvine Vice Chancellor. Richard Buffum, writing in the Los Angeles Times, reports the view of Tim Knowles, the deposed director of the EOP program at that institution, as follows:

Neither ethnic group [blacks and chicanos] ... is prepared to lie down docilely and accept the melting pot theory or racial and cultural assimilation-particularly when it is imposed arbitrarily and callously from above by 
"the man." Minorities, committed to their proud struggle to discover their unique identities, to create their own destinies by making free choices, deeply resent the whites knowing what's best for them and lowering the boom.

White liberals especially, it seems, are obsessed with opening doors for minorities, then emasculating them in the system (Buffum, 1971: 1).

Buffum adds his own accurate inference that, "The struggle for broad human rights is an agonizing conflict between the tyranny of cultural chauvinism and the tyranny of each individual's personal sense of uniqueness and worth" (Buffum, 1971: 1). In the Black English issue, cultural chauvinism just now has the decided edge, at least in Southern California.

The linguist who has seen this clearly and stated it most forcefully is James Sledd. He has bluntly labeled bi-dialectalism the "linguistics of White supremacy."

The immorality of that effort ... at trying to turn black people into uneasy imitations of the whites . . is the chief reason why enforced bi-dialectalism should not be tolerated even if it were possible. Predators can and do use dialect differences to exploit and oppress, because ordinary people can be made to doubt their own value and to accept subservience if they can be made to despise the speech of their fathers. Obligatory bi-dialectalism for minorities is only another mode of exploitation, another way of making blacks behave as whites would like them to. It is unnecessary for communication, since the ability to understand other dialects is easily attained, as the black child shows when she translates her teacher's prissy white model "his hat" into "he hat": its psychological consequences are likely to be nervous affectation, self-distrust, dislike for everyone not equally afflicted with the itch to get ahead, and eventual frustration by the discovery that the reward for so much suffering is intolerably small (Sledd, 1969: 1314-1315).

It may be, in addition, that the whole effort is based on a mistaken assumption that blacks are denied jobs and opportunity chiefly because of their dialect. Sledd and others have charged that northern employers and labor leaders react against black faces and use Black English as an excuse. Certainly, one wonders if such enormous energy, talent, and money as is invested in the bi-dialectalism program couldn't, in the long run, pay off better if invested in the more profound social change that seems needed to finally grant justice and freedom to black people.

For in the final analysis enlightened bi-dialectalism, like eradication, is nothing more or less than an attempt of the educational institution and society in general to cover up their own failures. Instead of adjusting to the social realities in America today, the school seeks to remedy its failure to meet the needs of black and other minority groups in the school by focusing on supposed personal deficiencies; it seeks to engineer the students to fit into the system, instead of changing the system to meet the needs of minority students who, naturally enough, do not respond to the nineteenth-century WASP structure the educational system seeks to impose.

There is some comfort in the thought that bi-dialectalism is not the worst of options. Arthur Jensen, an educational psychologist, was a leading proponent of the deficit theory; he has recently suggested that scientists ought to test the hypothesis of the genetic inferiority of Negroes. This move from the deficit theory of Black English to the deficit theory of black people may at first seem tangential to the central concern of this discussion, but it is directly relevant, and it is a worse option than bi-dialectalism. I have suggested that the bi-dialectal movement is merely covert eradication and that the basic 
fallacy of these movements is in tracing the educational failures of the black to his personal deficiencies. There has always been the alternative to blame the educational institution for not working. None of the verbal deprivation theorists chose to investigate this possibility, possibly because the school in our culture has such a monopoly over attitudes that it can choose and certify its own critics. Perhaps, too, this monopoly explains why linguists challenged the deficit theory and why some linguists have questioned the wisdom of the bi-dialectal movement: because the prescriptive notion has been the school notion, and the descriptive notion the linguistic notion, there has always been a certain contrariety between linguists and schools. This mutual distrust may have placed the linguist in a better position to criticize the institution.

At any rate, Jensen's movement in opting for the "inevitable hypothesis" of genetic inferiority of the Negro people to explain the educational failure of the urban ghetto black represents the ultimate in the protection of the institution and the logical extension of the verbal deficit theory. There is nothing new about the Jensen option in the history of our race relations-after all, the "best science" of the nineteenth century was able to demonstrate the genetic inferiority of blacks by the fact that Ethiopian skulls held fewer dried seeds than Caucasian skulls. Jensen used, for example, studies that purport to show that almost half of lower-class children are mentally retarded, a demonstration equally as ridiculous but more sophisticated in twentieth-century terms. So it is not new, but the option is nonetheless a severe threat because it goes beneath the normal cultural tensions to throw doubt on the touchstone of our cultural existence, and it is not a member of the Ku Klux Klan doing this. It is an honorable but benighted member of our central institution, the school, doing so in defense of that institution, and doing so not in some fly-by-night racist newsletter, but in the Harvard Educational Review.

Compared to Jensenism, to which it is related distantly, the bi-dialectal option seems down right desirable. Nevertheless, the nature of language and speech communities suggests other options.

The ultimate saving option lies in the nature of linguistic authority. The only kind of authority the eradicationists or bi-dialectalists seem to recognize is the formal authority of the classroom-the systematized, conscious drill in linguistic behavior. But linguists are confident that this authority is considerably less effective than the natural nurse of the speech community-informal authority. Informal authority is the natural, unforced, largely unconscious tendency of people who habitually speak to each other to adjust their linguistic behavior to the behavior of others in the community. Informal authority is always at work and its force is inevitable. If a person changes speech communities, informal authority will work on him until his speech habits adjust to those of the new community, at least to the point that his speech is not noticeably alien. If a person chooses not to change his community and to retain his linguistic identity, he may just as properly do this.

The point is that "code-switching" (as it is termed in sociolinguistic jargon) is a well-known phenomenon. Sociolinguists agree that there are no single-style speech communities (Sledd, 1969: 1314-1315). Therefore, the advocates of enforced bi-dialectalism do not go amiss in assuming that switching is theoretically possible. The problem is that the bi-dialectalists actually have the whole process backwards. Dialect change is more naturally the consequence of social change than it is the cause of it. If a speaker of Black English is first given a job that offers him opportunities for mobility, and if he does as a result change communities, his speech, through the agency of informal authority, will change to reflect the speech of his new community. If a ghetto child relates in a healthy way to education and becomes an educated person, he will acquire the cultivated social dialect as a result of this process-through reading and by speaking habitually to other cultivated 
speakers. This process requires some time and patience on the part of linguistically uptight teachers, but it will happen if the student makes the commitment to join the educated speech community.

The bi-dialectalists go amiss, then, in putting the linguistic cart before the linguistic horse. They are motivated in this, it would seem, by the intense cultural pressure of the notion of mobility, coupled with the strong continuity of prescriptivism with its drive for uniformity and conformity. The Black English problem is, linguistically speaking, a phony problem, but given the nature of American culture it is real and crucial. Because Americans have such a mania for correctness and are so neurotic about differences in speech habits that make no real difference as far as communication is concerned, one cannot simply ask that employers and teachers without effort relax their holy linguistic watchfulness and let the natural informal authority of the speech community enforce sufficient linguistic conformity so that people who need to talk together can, as communities have done informally at least since there has been anything known about language. It is probably too much to suppose that teachers and employers can without effort merely concentrate on people's skills, character, and potential, or as Langston Hughes put it, "digging and being dug in return."

The value configuration drawn from the data of this study will not admit this solution. The melting-pot, prescriptive values of the school system and the co-optive strategy used so effectively by the culture operates to exclude a more pluralistic ethic. The failure of twentieth-century relativism to penetrate the school's value system so far as "English" is concerned has virtually frozen the school in the nineteenth century in terms of linguistic attitudes.

\section{References}

Baratz, Stephen S. and Joan C. Baratz

1969 "Negro ghetto children and urban education: a cultural solution." The Florida FL Reporter 7 (Spring/Summer).

Baratz, Joan C.

1969 "Who should do what to whom . . . and why?" The Florida FL Reporter 7 (Spring/Summer).

Bolinger, Dwight

1968 Aspects of Language. New York: Harcourt, Brace \& World.

Buffum, Richard

1971 "The right to compete." Los Angeles Times (February 9), Part II.

Dillard, J.L.

1966 "The urban language study of the center for applied linguistics." The Linguistic Reporter 8 (October).

1967 "A program for overcoming the handicap of dialect." New Republic (March 25).

Goodman, Kenneth S.

1967 "Dialect barriers to reading comprehension: dimensions of dialect." Champaign, III.: National Council of Teachers of English. 
Kaplan, Robert F.

1969 "On a note of protest (in a minor key): bi-dialectism vs. bi-dialectism." The Florida FL Reporter 7 (Spring/Summer).

Kochman, Thomas

1969 "Social factors in consideration of teaching standard English." The Florida FL Reporter 7 (Spring/Summer).

Labov, William

1969 "The logic of non-standard English." The Florida FL Reporter 7 (Spring/Summer).

Shuy, Roger W.

1969 "Bonnie and Clyde tactics in English teaching." The Florida FL Reporter 7 (Spring/Summer).

Shuy, Roger W., Walter A. Wolfram and William K. Riley

1967 Linguistic Correlates of Social Stratification in Detroit Speech. East Lansing, Michigan: Michigan State University.

Sledd, James

1969 "Bi-dialectism: the linguistics of white supremacy." English Journal 58 (December). 